\title{
Tradição disciplinar e o desafio de construir currículos: recepções à $\mathrm{BNCC}$ para o componente de história ${ }^{1}$
}

\author{
João Maurício Gomes Neto*
}

\begin{abstract}
RESUMO
O presente artigo trata da primeira Base Nacional Comum Curricular/BNCC, área de História e da recepção desta frente a entidades de representação profissional. Neste sentido, objetiva mapear parte das críticas formuladas ao documento, por meio de manifestações públicas e compreender em que sentido elas dialogam com as concepções projetadas para o ensino de história na educação básica. Ao centrar-se na recepção da versão inicial da Base, depois alterada em sua quase totalidade, a intenção é compreender parte dos motivos que levaram a reafirmação de um currículo calcado na centralidade dos conteúdos e na perspectiva de sua organização quadripartite, em cronologia linear. Ao recorrer a conceitos de colonialidade do poder e do saber para pensar a questão, a hipótese norteadora da investigação é de que tal escolha evidencia, principalmente, dois elementos: por um lado, a historicidade da organização curricular do componente de história no país, a despeito de todas as críticas e questionamentos sofridos, inclusive por aqueles que a mantém como tal nos cursos de formação de professores desta área nas universidades; e por outro, interesses vinculados às diversas subáreas que a divisão quadripartite da história acabou por criálos e difundi-los.
\end{abstract}

Palavras-chaves: Ensino de história. BNCC de história. Colonialidade.

\section{Democracy, disciplinary tradition and the challenge of building curriculums: receptions to BNCC towards history component}

\begin{abstract}
The present article treats the first National Common Curricular Basis/BNCC, area of History and its reception facing entities of professional representation. In this sense, it aims to map part of the critiques formulated to the document, by means of public manifestations and understanding in which way they dialogue with the conceptions projected to the teaching of history in basic education. By centering in the reception of the Basis initial version, later altered almost in its totality, the intention is to comprehend part of the reasons that took the reaffirmation of a curriculum established in the centrality of contents and in the perspective of its quadripartite organization, in linear chronology. Appealing concepts of coloniality of power and knowing to think the question, the guiding hypothesis of the investigation is that such choice highlights, mainly, two elements: on the one hand, historicity of curricular organization of the history component in the country, despite of all critiques and questionings suffered, including by those who keep it as such in the courses of teachers training of this area in the universities; and, on the other hand, interests linked to many subareas in which quadripartite division of history has turned out to creating and disseminating them.
\end{abstract}

Keywords: Teaching of History. BNCC of History. Coloniality.

\footnotetext{
" Doutor em História pela Universidade Estadual Paulista "Júlio de Mesquita Filho"/Unesp, campus de Franca/SP. Docente formador de professores(as) vinculado ao Departamento de História da Universidade Federal de Rondônia/Unir, campus de Rolim de Moura. Atua sobretudo nas sub-áreas de história moderna e contemporânea. Email: joao.mauricio@unir.br.
} 
Artigo recebido em 30 out. 2018.

Aprovado em 5 mai. 2019.

\title{
Preâmbulo. Ou uma nota conceitual
}

\begin{abstract}
A elaboração intelectual do processo de modernidade produziu uma perspectiva de conhecimento e um modo de produzir conhecimento que demonstram o caráter do padrão mundial de poder: colonial/moderno, capitalista $e$ eurocentrado. Essa perspectiva e modo concreto de produzir conhecimento se reconhecem como eurocentrismo.

Eurocentrismo é, aqui, o nome de uma perspectiva de conhecimento cuja elaboração sistemática começou na Europa Ocidental antes de mediados do século XVII, ainda que algumas de suas raízes são sem dúvida mais velhas, ou mesmo antigas, e que nos séculos seguintes se tornou mundialmente hegemônica percorrendo o mesmo fluxo do domínio da Europa burguesa. Sua constituição ocorreu associada à específica secularização burguesa do pensamento europeu $e$ à experiência $e$ às necessidades do padrão mundial de poder capitalista, colonial/moderno, eurocentrado, estabelecido a partir da América (Quijano in Lander, 2005, p. 115) ${ }^{2}$
\end{abstract}

As palavras acima são de Anibal Quijano, um dos expoentes da chamada perspectiva decolonial e que costuma problematizar em seus escritos a presença ou a herança do colonialismo nas formas de organização social contemporâneas, nas relações pessoais e até na maneira como dizemos, lemos o mundo.

A hipótese de Quijano (2005) seria a seguinte: a despeito de estarem relacionadas, modernidade e colonialidade foram geralmente tratadas como experiências separadas, bifurcadas entre um lá e um cá. Tal distinção, conforme o autor, também questionada por Walter Mignolo (2003) e Enrique Dussel (2005), partia da premissa segundo a qual a modernidade seria uma experiência/questão europeia, ao passo que a colonialidade seria vigente fora daquele continente, sobretudo na chamada América.

Neste sentido, a "colonialidade do poder" e "do saber" ${ }^{3}$ não seriam perspectivas vigentes apenas no país colonizador, tanto que internamente, nas ex-colônias, a divisão do poder e do saber teria, numa relação de continuidade, se realizado a partir de premissas eurocentradas, mesmo após os processos de independência. Qual seja, "histórias locais que absorveram projetos globais", tal como sugere Walter Mignolo (2003, p. 82).

As considerações de Anibal Quijano, Henrique Dussel e Walter Mignolo, para não se estender em demasia, me levam a observar como temos adotado, de bom grado, o colonialismo, sem refletirmos sobre os sentidos e os motivos de nossa servidão voluntária. Inclusive ao pensar a história, ao projetarmos e discutirmos currículos para a área. É esta discussão que tento travar nas 
páginas seguintes, tendo por estudo de caso recepções à Base Nacional Curricular Comum/BNCC para a história e no horizonte conceitual, provocações mobilizadas a partir da perspectiva decolonial.

\section{Os marcos legais da Base Nacional Comum Curricular/BNCC e a história quadripartite}

Estas considerações poderiam ser iniciadas a partir de incontáveis assertivas. Contudo, por fatores que espero delimitá-los no decorrer deste artigo, gostaria de ponderar sobre os desafios de construir currículos. Ao fazê-lo, sei que recaio em um senso comum. Ainda assim considero válido e necessário ponderar: elaborá-los significa evidenciar e colocar projetos e concepções de sociedade em confronto, em disputa ${ }^{4}$.

Dada a tradição pouco democrática do estado brasileiro, desde datas longínquas, as práticas autoritárias e a construção de regimes de exceção que podam e limitam a efetivação da cidadania no Brasil é algo constituinte de nossa cultura política ${ }^{5}$. Talvez pelos traumas somados nessa longa trajetória, as iniciativas do estado, quando dizem respeito às políticas públicas, sobretudo no campo da educação, sejam recebidas e percebidas com desconfiança por atores sociais, grupos e entidades de representação profissional. A área de história não foge a esta regra.

Em momentos distintos e em atenção a interesses diversos, a história foi tornada campo de disputas fundamental à orientação de valores e projetos de sociedade que se queria fomentar; ao passo em que se silenciava e excluía outros. À guisa de exemplos, perceber as concepções de história defendidas e propagadas quando da instituição do regime republicano (1889), pela ditadura de Vargas (1937-1945) ou durante a ditatura civil-militar (1964-1985) são elucidativas a este respeito.

Compreender essa trajetória contribui para elucidar, imagino, parte da resistência manifestada por profissionais de história, por meio de suas entidades de representação, ao tomarem conhecimento da proposta da BNCC para esta área, cuja primeira versão foi tornada pública em 23 de setembro de 2015. Contudo, entendo existirem outras questões envolvidas neste percurso.

Documentos semelhantes são comuns em praticamente todos os estados nacionais contemporâneos, a exemplo do que ocorre na Argentina, Estados Unidos, Finlândia, México, Japão, Portugal, Inglaterra entre outros. Em parte desses países, as reformulações dos currículos ocorreram diversas vezes, procedimento comum, se se entende que a elaboração e implementação deles é um processo dinâmico e afeito a constantes adaptações. 
No Brasil, os marcos legais que orientam a elaboração de currículo mínimo à educação básica estão dados desde a Constituição de 1988. Nela, no artigo 210, em seu título III (Da Educação, da Cultura e do Desporto), Seção I, a qual dispõe especificamente sobre educação, consta: "Serão fixados conteúdos mínimos para o ensino fundamental, de maneira a assegurar formação básica comum e respeito aos valores culturais e artísticos, nacionais e regionais" (BRASIL, [1988], 2018) .

Tal disposição seria reiterada na LDB (Lei de Diretrizes e Bases n 9.394, de 20 de dezembro de 1996), no item IV do artigo $9^{\circ}$. Neste, ao relacionar as competências da União no tocante à educação, destaca-se: "estabelecer, em colaboração com os Estados, o Distrito Federal e os Municípios, competências e diretrizes para a educação infantil, o ensino fundamental e o ensino médio, que nortearão os currículos e seus conteúdos mínimos, de modo a assegurar formação básica comum" (BRASIL, [1996] 2018).

Pode-se fazer críticas justas e legítimas, seja à Constituição seja à LDB, mas dizê-las antidemocráticas e que durante suas elaborações não se efetivou amplo e intenso debate, envolvendo grupos sociais de interesses distintos, é provável que não seja uma delas. Entrementes, a construção do currículo mínimo comum, previsto na Constituição, reiterado e ampliado pela LDB, ao incluir o ensino médio, nunca havia sido levada a cabo e nem regulamentada por lei específica.

O documento que mais se aproximou de um currículo mínimo foram os Parâmetros Curriculares Nacionais (PCN, PCN + e PCN em Ação), publicados na segunda metade da década de 1990, mas cuja própria designação acentuava, destinavam-se mais às orientações ou a construção de parâmetros, sobre os quais deveriam centrar-se o processo de ensino-aprendizagem, sem disporem de efeito normativo.

Os Parâmetros de história foram organizados num misto de história temática e história cronológica linear, com listagem de conteúdos que poderiam nortear a operacionalização de parte das propostas ali contidas, o que aproximava-os de um currículo básico, mesmo que não fosse este o objetivo legal ${ }^{7}$ do documento e que tenha sido usado e apropriado como tal, seja pelo mercado editorial de livros didáticos (sobretudo nas orientações constantes nos Manuais do Professor), seja pelo governo federal, quando via antigo Fundef, costumava incentivar o uso dos PCN nas escolas, destinando recursos financeiros adicionais àquelas que diziam orientar suas propostas curriculares por eles.

Passadas quase três décadas desde a promulgação da Carta de 1988, em todas as áreas, os currículos do ensino básico continuavam orientados pela tradição acadêmica universitária, que 
organiza e estrutura os cursos de graduação no país; e por editores e autores de obras didáticas, partilhando e reforçando a tradição mencionada.

No caso da história, o modelo quadripartite (dividido em antiga, medieval, moderna $e$ contemporânea $)^{8}$, eurocêntrico, reiteradamente criticado e igualmente reproduzido em quase totalidade dos Projetos Pedagógicos dos Cursos/PPC de história do país, continuava hegemônico.

$\mathrm{Na}$ educação básica tal modelo quadripartite também se manteve na área de história, conforme se percebe pela organização da maioria dos livros didáticos, os quais na ausência do currículo mínimo, têm assumido o lugar e a função de currículo efetivo, a despeito do dedo apontado, dos reclames e lamentos de acadêmicos/especialistas, geralmente universitários, que sugerem a teimosia ou a esquiva competência dos professores da rede, cujas práticas, supostamente, não se atualizam e reproduzem um ensino de história dito tradicional, centrado na "decoreba" de conteúdos, desprovido de sentido e pouco atrativo aos estudantes, perspectiva esta, por certo, distinta daquela praticada pelos docentes nas universidades, cujos PPCs dos seus cursos replicam o modelo que criticam nas escolas.

A levar em consideração estas críticas, deveria ser realmente fato intrigante se os professores do ensino básico, formados pelas universidades, apresentassem práticas tão dissonantes daquilo que supostamente tiveram em seus cursos de formação, cuja estruturação continua subdividida nos quatro grandes recortes temporais já sabidos. Afinal, conjectura-se, faz tempo que os cursos desta área abandonaram a perspectiva dita tradicional, conteudista, quadripartite e eurocêntrica.

Cabe ponderar ainda, que os dispositivos legais já citados, somados a outros, como o Plano Nacional da Educação/PNE e as Diretrizes Curriculares Nacionais Geral para a Educação Básica (DCNE), não elucidam sozinhos esta movimentação em torno da elaboração da BNCC.

No âmbito do componente de história, por exemplo, são adensados a estes dispositivos legais, eles também resultado de disputas e demandas sociais, as mudanças substanciais sofridas pelo Programa Nacional do Livro Didático/PNLD, a partir de 2004, quando este passou a ser orientado por editais públicos.

Por isso, desconfio e sugiro que perscrutar os editais deste programa ${ }^{9}$, possibilitará compreender parte dos deslocamentos realizados, com vistas a atender às demandas e questões colocadas pelos avaliadores (docentes do ensino básico, professores formadores de professores e/ou pesquisadores especialistas em diversas subáreas ${ }^{10}$ de atuação) e representantes dos movimentos sociais, para quem o componente de história, mais do que qualquer outro, é percebido como palco privilegiado e fundamental à representação histórica desses grupos, demanda essa entendida e colocada, inclusive, em condição estratégica à efetivação da cidadania. 
São exemplos disso as leis 10.639 e 11.645 que alteraram a LDB e tornaram obrigatórios o Ensino de História e Cultura Afro-Brasileira e Indígena em todos os níveis de ensino da educação no país. Se esta situação é notável, por ter sido instituída por força de lei, as demandas por representação histórica não pararam por aí: mulheres e questões de gênero, a diversidade de arranjos familiares, os movimentos LGBTQIA, os idosos entre outros grupos e movimentos sociais passaram a pleitear o direito à representação, tornando o currículo de história arena ainda mais disputada.

Desprovido de um currículo mínimo norteador e cada vez mais demandados, os livros didáticos de história foram eleitos palco privilegiado para dar conta desses litígios. Ao fazê-lo, implícita ou explicitamente, os grupos sociais entendiam que eram essas obras quem definiam o currículo no país e por isso, a disputa por representação deveria ser travada nessa arena. Impelidos por esses pleitos e sem dispor de um documento base, os editais do PNLD procuraram - e esta é uma hipótese minha - acompanhar os debates e proposições, tanto dos grupos e movimentos sociais; quanto dos professores/pesquisadores/especialistas, com vistas a influir e orientar de alguma forma, os desafios que estavam postos.

Considerei importante traçar esse percurso por entender que ele fornece e ajuda a compreender parte relevante das motivações que levaram a termo a proposição e a construção da BNCC, que tem peso de lei.

\section{A primeira versão da BNCC do componente de história e a proposta de organização curricular temática}

A primeira versão da $\mathrm{BNCC}$ de história fugia a divisão quadripartite tão reproduzida $e$ igualmente questionada pela historiografia, destacadamente pela subárea de pesquisadores do ensino deste componente curricular. A organização se dava em recortes espaciais que iam do local ao regional, deste ao nacional e da nação ao global ${ }^{11}$ por eixos temáticos assim distribuídos: sujeitos e grupos sociais; grupos sociais e comunidades; comunidades e outros lugares de vivências; lugares de vivências e relações sociais; mundos brasileiros; representações, sentidos e significados do tempo histórico; processos e sujeitos e análise de processos históricos (para os últimos dois anos).

Estes eixos temáticos procuravam dialogar com objetivos elencados para o ensino fundamental nos anos iniciais e finais. 
A percepção da historicidade presente em questões do cotidiano favorece a compreensão do passado de pessoas, individual e coletivamente, em suas dimensões política, econômica, cultural e social. Nesse sentido, aos anos iniciais cabe a construção das noções fundamentais do saber histórico (por meio do estudo com fontes e documentos, noções de tempo, sujeitos, permanências $e$ mudanças) e o trato inicial com processos históricos.

Aos anos finais do Ensino Fundamental cabe o desenvolvimento de conhecimentos necessários ao enfrentamento de processos históricos, enfatizando-se o estudo da História do Brasil e de indivíduos e coletividades que demarcaram mudanças e permanências nas conformações sociais, econômicas, culturais e políticas da trajetória histórica brasileira, o que envolve, como sinalizado anteriormente, o estabelecimento de nexos com processos ocorridos em outras partes do mundo, marcadamente nas Áfricas, nas Américas e nos mundos europeus. (BRASIL, 2015, p. 244)

No componente de história a estruturação curricular temática tem potencial para mobilizar conteúdos e conceitos a partir de problemáticas, nas quais estão presentes categorias como tempo e espaço, passíveis de serem trabalhadas em recortes e escolhas diversas, a depender de critérios estabelecidos pelos docentes, entre os quais se situam a realidade da sala de aula, da comunidade a qual pertencem professores e estudantes ou de questões demandadas à história, em determinados momentos pela sociedade.

Neste sentido, a organização curricular por temas não renuncia a cronologia e nem o trabalho com eventos e fatos tornados "canônicos" pela historiografia, conforme se observa nos objetivos elencados na Base para área de história; mas pode mobilizá-los e colocá-los em diálogo e evidência de maneira fugidia à exposição linear. Cabe lembrar que mesmo naturalizado pelo uso recorrente, a apresentação de conteúdos em ordem cronológica também resulta de recorte e escolhas operacionalizadas por profissionais de história.

Outro aspecto que se efetivou na BNCC e que conforme ver-se-á, adensou o coro das críticas, foi tomar a chamada História do Brasil como ponto de partida, não de chegada. Assim, se inverteu a lógica da organização do currículo posta até então, o que a levou a ser considerada entre outras adjetivações, "brasilcêntrica".

Na organização curricular temática, entende-se que o profissional/professor poderá dispor de maior autonomia para selecionar os conteúdos e conceitos que entende mais prementes $e$ estratégicos ao desenvolvimento crítico/reflexivo dos estudantes. Para ilustrar a questão, cito dois exemplos ${ }^{12}$, fora da Base, pondero:

O primeiro: na discussão a respeito dos conceitos de identidade/alteridade ou da "invenção do outro", poderia ser trabalhada a relação que os gregos mantinham com povos estrangeiros (história antiga); como europeus (espanhóis e portugueses) construíram imaginários sobre os indígenas, no que se inclui a própria definição de índios, em detrimento das autodenominações destes povos (histórias moderna e contemporânea); ou ainda, em termos historiográficos, a 
construção operada pelos "modernos", na relação que estabeleceram com os "antigos", ao ponto de classificarem determinado período da experiência histórica como medievo, também adjetivada de "idade das trevas".

Esta operação teria potencial, imagino, de fazer os estudantes compreenderem que além de estudar a construção de identidades e alteridades, a própria narrativa histórica também as criou e construiu, em várias espacialidades e temporalidades. Seria também momento rico para se pensar a própria escrita da história, qual seja, para se problematizar potencialidades, limitações e vícios comuns às representações historiográficas, a partir de experiências diversas, sem descartar cronologia e trabalhando com os chamados conteúdos substantivos.

O segundo: movimento análogo, agora partindo da experiência histórica rondoniense (história local/regional ${ }^{13}$ ), poderia ser desencadeado tomando por questão problematizadora as noções de: progresso, pioneiros ou novos bandeirantes, tão reiteradas e comuns, seja na historiografia, seja em textos de memorialistas migrantes deste estado. Nestas narrativas, a chegada e construção das vivências desses sujeitos em Rondônia são compreendidas, geralmente, como sinônimo da efetivação dos ideais de civilização, modernidade e progresso (aqui pode-se ir da história local/regional à história global).

Problematizar o uso recorrente dessas palavras/conceitos (civilização, modernidade, progresso, pioneiros, bandeirantes) pode dizer muito a respeito da forma segundo a qual se vê a história e nela se percebe a si mesmo e ao outro (identidade/alteridade). Para tanto, caberia reorganizar os conteúdos substantivos a partir de questões, mobilizando para isso o recurso fundamental às perguntas: a que se contrapõe a ideia de progresso? $\mathrm{O}$ que é entendido como progresso nessas narrativas? E o que é dito e descrito como seu contrário, qual seja, atrasado? Como isso se vincula ao imaginário de modernidade, tão estudado pela historiografia? Quando se fala em "destemidos pioneiros" e em "novos bandeirantes", que outras experiências históricas são reatualizadas?

A primeira versão da BNCC continha lacunas e era passível de mudanças $e$ aperfeiçoamentos. Daí a importância de promover-se o debate e de sua submissão ao crivo da academia, da comunidade escolar e da sociedade civil. O reclame de que o tempo para consulta e sugestões de alterações era exíguo, não deve ser desconsiderado. Entrementes, conforme já explicitado, a ideia aqui é menos discutir a Base em si e mais tentar compreender parte das motivações que levaram o texto a ter recepção tão reativa por entidades representativas dos profissionais de história. 


\section{Recepções à primeira versão da BNCC do componente de história}

Entre setembro de 2015 e abril de 2017, três versões da BNCC foram levadas ao conhecimento público, num processo que envolveu discussão intensa e manifestações de toda sorte, principalmente na área de história. A proposta aqui não é comparar os documentos final e inicial, com vistas a estabelecer qual deles seria o mais adequado (ainda que um estudo comparativo das versões apresentadas ofereça rica discussão a respeito de temas diversos, a exemplo das concepções de história, do lugar e papel social desta na formação para a cidadania, das percepções e direcionamentos sobre ensino-aprendizagem histórica e da construção de currículos), mas compreender o peso da organização disciplinar quadripartite e do primado dos conteúdos no componente de história. Este objetivo direcionou a seleção das notas públicas/manifestações selecionados para discussão no presente artigo.

A este respeito, dada repercussão que teve, centro-me em aspectos da primeira versão, pois a recepção a ela contribui, no meu entendimento, à compreensão de parte das interseções ou da ausência delas - no debate que envolve conhecimento histórico acadêmico, conhecimento histórico escolar, formação de professores da área e o objetivo do componente história na educação básica.

Foram vários os comentários, pareceres, propostas concorrentes, notas e cartas públicas (de repúdio, inclusive) publicados por professores, pesquisadores e entidades de classe. Entre estas últimas, constam manifestações da Associação Brasileira de Estudos Medievais/ABREM; da Seção Regional da Associação Nacional de História, ANPUH-RJ; de Professores de História Antiga e Medieval do Norte e Nordeste; do Núcleo de Estudos Mediterrâneos/NEMED-UFPR; do Laboratório de Ensino de História do Recôncavo da Bahia/LEHRB-UFRB; do Departamento de História do Colégio Pedro II; da Associação Nacional de História, ANPUH-BR; da Seção Regional da Associação Nacional de História, ANPUH-RS; da Seção Regional da Associação Nacional de História, ANPUH-PR; do Fórum de professores de História Antiga e Medieval; do GT de História Antiga e Medieval vinculado à Seção Regional da ANPUH/SC; do GT de História da África da ANPUH-Brasil e da Associação Brasileira de Estudos Africanos (ABE-África); do Grupo de Estudos de História Antiga (GTHA) e da Associação dos Professores de História das Américas/ANHPLAC ${ }^{14}$.

Para a presente exposição, por questões de recorte, não me deterei a todas as manifestações. Seleciono algumas delas sobretudo a partir daquilo em que me aparentam convergentes, centrado ainda na perspectiva de história quadripartite e no que reputo ser expressivo da "colonialidade do saber" acadêmico. Destaco ainda o depoimento público realizado 
em redes sociais e a entrevista concedida pelo ex-ministro da educação, Renato Janine Ribeiro, obviamente, pelo posto central que ocupou.

A primeira versão da BNCC foi publicada em 15 de setembro de 2015. Todavia, para surpresa geral, a parte referente ao componente de história estava ausente, o que gerou surpresas e questionamentos vários. O documento referente a essa área só foi colocado a apreciação pública em 23 de setembro do mesmo ano.

Tal atraso ocorreu porque ao tomar conhecimento da proposta apresentada pela área de história, o então ministro da Educação, Renato Janine Ribeiro, censurou, "retardou" sua publicação imediata e tentou convencer os membros da comissão ${ }^{15}$ que havia sido designada a alterá-la antes de torná-la pública, para conhecimento, críticas e contribuições. Como a comissão recusou-se a alterar a proposta antes da apreciação pública, ela foi finalmente publicada em 23 de setembro.

Nas redes sociais (Facebook), em 08 de outubro daquele ano, já na condição de exministro, Renato Janine Ribeiro se pronunciou nos seguintes termos ${ }^{16}$ :

A base nacional comum. Não sou mais responsável por ela, mas preciso esclarecer um fato sobre a base de História. Primeiríssimo de tudo, deixei claro como água que o texto inteiro da Base que foi divulgado NAO era um documento oficial do MEC, mas uma proposta elaborada a convite dele. Portanto, quem o quiser criticar que o faça, mas sem atribuí-lo ao MEC. Banal, isso.

Mas o fato é que o documento de História tem falhas. Tanto assim que retardei sua publicação e solicitei ao grupo que o elaborou que o refizesse. Mas eles mudaram pouca coisa. Mesmo assim, com o enfático alerta de que não era um documento oficial, acabei autorizando sua publicação.

O que eu pensava para a base comum em História era que ela tratasse da história do Brasil e do mundo, sendo que esta não se deveria limitar ao Ocidente e seus precursores, mas incluir - desde a Antiguidade - a Ásia, bem como a África e a América pré-colombiana. Primeiro de tudo, uma história não eurocêntrica.

Segundo, uma história que não se concentrasse, como era costume muito, muito tempo atrás, nos reis e grandes homens, mas tratasse de tudo o que a disciplina foi estudando nas últimas décadas - mentalidades, economia, rebeliões, cultura. $\mathrm{O}$ documento entregue, porém, na sua primeira versão ignorava quase por completo o que não fosse Brasil e África. Pedi que o revissem. Pedi ao FNDE os livros didáticos mais solicitados. Examinei-os. Vi que começavam geralmente no 6.o ano do Fundamental com a Antiguidade, mas nunca se confinavam às "raízes do Ocidente" e sim iam para os outros continentes etc etc. Não se bastavam nos reis, mas mostravam rebeliões, divergências etc. Eles me pareceram muito razoáveis.

Mas o grupo que elaborava a base não entendia assim. Não havia sequência histórica. Queriam partir do presente para ver o passado. No caso do Brasil, $\mathrm{p}$ ex, propunham a certa altura estudar revoluções com participação de escravos ou índios. E deixavam de lado a Inconfidência Mineira! Certamente, porque o espírito dela era bem pouco abolicionista. Solicitei expressamente que ela fosse incluída. Você pode até discordar dos inconfidentes, criticá-los, mas tem que conhecê-los.

Não havia, na proposta, uma história do mundo. Quando muito, no ensino médio, uma visão brasilcêntrica das relações com outros continentes. 
Mesmo assim, disse, acabei aceitando que fosse publicada. Mas determinei que alguns dos melhores historiadores brasileiros fossem chamados para discuti-la. Um dos convidados, só para se ter ideia da grandeza dos seus nomes, é Boris Fausto. E as discussões que estão surgindo, algumas delas com críticas duras, deverão ser levadas em devida conta. Aliás, ontem mesmo se reuniu uma equipe de matemáticos para discutir essa área - incluindo, claro, um representante do IMPA. O Secretário Palácios procurou os melhores pesquisadores para essa discussão, que virá junto com todas as outras discussões.

Desculpem-me tratar de assunto que já não me compete. Mas eu o dirigi, e por tudo o que sei o Ministro Mercadante e o secretario Palácios evitarão qualquer viés ideológico neste tema e em outros.

Finalmente: na transmissão do cargo, ontem, deixei claro que pretendia, da base de História, que desse um ensinamento crítico, "mas sem descambar para a ideologia". É direito de todo jovem saber o trajeto histórico do mundo. Precisa aprender sobre a Renascença, as revoluções, muita coisa. Mas não há uma interpretação única de nenhum desses fenômenos. E é esta diversidade que a educação democrática e de qualidade deve garantir. (Ribeiro, [2015] 2018).

No dia seguinte, qual seja, em 9 de outubro, em entrevista ao portal de notícias das Organizações Globo, o G1, o ex-ministro reiterou:

Fiz questão de deixar claro que a proposta não era oficial do governo, porque ela ia ser acusada pela falta desse repertório básico, disse Janine.

Procurado pelo G1, o Ministério da Educação disse que o programa curricular foi elaborado por professores de universidades federais, e que não comentaria a publicação feita pelo ex-ministro. (G1, [2015], 2018)

Na mesma matéria, Renato Janine Ribeiro retomava os apontamentos realizados nas redes sociais a respeito do que, na concepção dele, seriam lacunas graves na BNCC de história apresentada:

Não havia História Antiga, não havia História Medieval. No caso do Brasil, o conteúdo partia de fenômenos atuais, como a discriminação racial, e daí partia para a questão da escravidão e dos indígenas. Mas deixava de lado a economia colonial e o que seria uma cronologia. Muitas pessoas discordam dessa visão, porque ela não dá ao aluno o repertório básico para discutir a história", disse Janine. (G1, [2015], 2018)

[...]

Se o aluno não estudou a Idade Média, o Renascimento, a Colônia, mas apenas estudou esses períodos em função da opressão, fica muito difícil ter depois condições de discutir isso. Por isso que, quando saiu o primeiro projeto deles, eu pedi que fosse reavaliada, e que eles tentassem algo com repertório com base no conhecimento da história. (G1, [2015], 2018)

Gostaria de destacar em primeiro lugar, a postura exclusiva e inédita adotada por Renato Janine Ribeiro em relação a esta área; e em segundo, as concepções de história explicitadas pelo ex-ministro em seu posicionamento público.

A Base de história foi tratada como documento NÃO oficial pelo MEC, prática que destoa totalmente da observada nas demais áreas. Este "não", cabe destacar, foi grafado em caixa alta 
pelo ex-ministro. Supõe-se que para deixar transparente, explícita sua posição de discordância. É um grito escrito! A proposta, a despeito de ter sido construída a convite daquele ministério, não seria dele.

O ex-ministro, ao que se sabe, não se manifestou publicamente, de forma específica, sobre as demais áreas e nem se sentiu autorizado a censurá-las ou a fazê-las críticas públicas. À matemática, também citada de forma breve na postagem dele, não é feita maiores considerações. É neste sentido que a área de história se constituiu em exceção nesse processo e isto diz muito, penso.

Para fins de compreensão, o MEC conta com representantes de cada área (Comissão Técnica) para responder por elas quando requisitado, seja por demandas internas (elaboração de políticas públicas) ou externas ao ministério (pedidos de esclarecimentos, críticas a materiais didáticos, entre outros). Geralmente, quando requisitado a manifestar-se a respeito de temáticas ou políticas públicas específicas, a assessoria daquela área é acionada e posicionamentos ou esclarecimentos são tornados públicos, por secretarias ou pelo ministro.

É de supor-se que causaria estranhamento se a censura prévia do ministro fosse feita aos documentos apresentados pelas áreas de ciências da natureza ou matemática, por exemplo. Mas no que diz respeito à história, além de retardar, sugerir mudanças e tentar demover a comissão de apresentar a proposta construída em equipe, o ex-ministro sentiu-se no direito de explicitar concepções pessoais a respeito, além de realizar consultas externas a outros especialistas, protocolo de certo inabitual, sobretudo ao se ter em vista que o documento seria posto à apreciação pública.

Ao ponderar essas questões, a intenção é convidar a refletir sobre o lugar central que a narrativa histórica ocupa no debate público nacional, mesmo quando tudo parece supor o contrário $^{17}$, a ponto de um ex-ministro, mesmo sem formação na área ${ }^{18}$, fazer intervenções $e$ censuras públicas a documento elaborado por especialistas, cuja formação e atuação é distinta da sua, a despeito dos diálogos e interseções necessárias e profícuas, envolvendo tanto as humanidades quanto às demais ciências.

As falhas apontadas pelo ex-ministro, conforme se viu, giram em torno da concepção de história e dos recortes espaciais e temporais nela implicados. No entendimento dele, na busca por fugir ao eurocentrismo, ter-se-ia caído no extremo oposto. Qual seja, uma perspectiva que conceituou de "brasilcêntrica", cujas escolhas deixariam de fora conteúdos entendidos por ele como fundamentais, sobretudo a respeito da antiguidade, do medievo e da modernidade.

Renato Janine Ribeiro também criticou a proposta de estar desprovida de cronologia, posto que não explicitava, em sequência linear, os eventos históricos; de ser ideológica - a escolha do "outro" tende a ser ideológica, sobretudo quando dissonante da nossa - e de não contemplar 
a diversidade de perspectivas interpretativas comuns à história. Portanto, deixaria a dever no quesito pluralidade, condição necessária à formação cidadã numa democracia. Seu embasamento foi reforçado, conforme explicitou, nas consultas realizadas aos livros didáticos da área e a historiadores renomados.

Em resumo conclusivo, a despeito de ter formação em filosofia, as lacunas ou falhas apontadas pelo ex-ministro convergiam de maneira sintomática com os posicionamentos públicos manifestados por diversas entidades representativas de profissionais de história, no que se inclui a maior delas, a ANPUH-BR.

A primeira manifestação pública ${ }^{19}$ de uma entidade representante de profissionais da área foi feita pela Associação Brasileira de Estudos Medievais/ABREM. Nela, se apontam graves problemas, entre os quais: a postura autoritária na condução do processo. Dá a entender que o documento é despropositado e antidemocrático. Questiona a constituição e competência dos membros da Comissão composta pelo MEC. E menciona a qualificação da subárea no cenário brasileiro, para validar seu posicionamento.

A nota segue na crítica aos recortes espaciais e temporais operacionalizados na Base, os quais supostamente deixariam de fora história antiga e medieval, subáreas cujas pesquisas forneceriam conteúdos substantivos e que seriam indispensáveis à formação dos estudantes do ensino básico. Ao operar tal escolha,

Na BNCC, sobressai, portanto, a supressão de conhecimentos que integram o patrimônio cultural do Brasil e a ênfase no estudo da História a partir do século $\mathrm{XVI}$. A academia não pode concordar com essas escolhas, dificilmente sustentáveis do ponto de vista científico. É tão evidente o equívoco dessa amputação que a própria Capes tem se inclinado ao fomento da História não nacional. Como fazer convergir a legitimidade e o reconhecimento da pesquisa nas áreas de Antiga e Medieval que a Capes e o CNPq têm dado a seus pesquisadores com a proposta do Ministério da Educação? A dissonância entre a distinção que as agências governamentais têm dado a associados da ABREM e a forma como a elaboração do documento, para os quais esses pesquisadores deveriam ter sido convocados a colaborar, é flagrante. A Associação, porém, desde seu início tem investido toda a sua energia na convergência, afinal agrega pesquisadores das áreas de Filosofia, História, História da Arte e Letras, e quer levar essa experiência à Base. (ABREM, [2015], 2018).

Só para fins de apreensão e reflexão inicial, a preocupação, ao que parece, centra-se mais no âmbito da pesquisa e menos na maneira como estas dialogam com a formação de professores e podem construir pontes com o currículo das escolas, os quais conforme é sabido, abarcam "Deus e sua obra", ou em termos mais adequados à laicidade ainda requisitada ao estado, toda história da humanidade, desde a chamada pré-história ao dia de ontem. 
Há de se destacar positivamente a preocupação expressada em aproximar a subárea da discussão sobre currículos e o ensino de história, o que é percebido quando busca argumentar os motivos pelos quais a presença de tais conteúdos seria fundamental ao currículo desta área no ensino básico, mesmo que tal proposição se atenha a excelência do quadro de pesquisadores que compõe a associação e silencie a respeito da diferença básica, porém fundamental, entre conhecimento acadêmico e conhecimento escolar.

O posicionamento da ABREM retomava, para reforçar seus argumentos, citação direta, de parte da Nota divulgada pelo Núcleo de Estudos Mediterrâneos/NEMED-UFPR, na qual, entre outras críticas, questionava o que entendia ser a priorização desproporcional conferida ao ensino de história da África, ao passo em que apontava fragilidades mesmo nesta última abordagem. E em tons conclusivos, destacava:

Está claro, portanto, que não se trata de "defender" a História Europeia ou de subscrever posições conservadoras, mas sim de se manifestar em favor do acesso a um patrimônio cultural diversificado, cujo conhecimento é fundamental em um mundo que passa por grandes transformações sociais, um mundo que tem colocado frente a frente diferenças que só a ciência do outro será capaz de fazer dialogar e acolher. Não estamos lidando apenas com as diferentes formas de se ensinar o passado, mas também com a formação de cidadãos, suas concepções a respeito da sociedade, sua inserção no mundo. Estamos falando de cidadãos em um mundo globalizado no qual, diga-se de passagem, as fronteiras tradicionais estão em transformação ou são radicalmente postas em xeque. Nesse sentido, a crítica da História Nacional, ou ainda, a incorporação da História Indígena ou da História da África, não constituem, em si, um problema. $\mathrm{O}$ problema está em fazer essa incorporação em detrimento de processos históricos que dão sentido ao mundo atual e mesmo às trajetórias dos povos dos continentes africano e americano após o final do século XV. (ABREM, [2015], 2018).

Ao tentar deslocar-se do eurocentrismo, privilegiando outros recortes, o que se operava, conforme o raciocínio explicitado acima, era a fragilização e o comprometimento da própria historicidade dos eventos e dos povos africanos e americanos, posto que após o final do século $\mathrm{XV}$, suas trajetórias e experiências dificilmente poderiam ser compreendidas fora dos contatos estabelecidos com os europeus. Ao que parece, mesmo escusando-se de subscrever posturas conservadoras, a colonialidade do poder e do saber poucas vezes foi expressada e assumida em nota pública com tamanha nitidez e vivacidade por entidade de representação profissional.

Para evitar esquecimentos prejudiciais à compreensão do raciocínio expressado pela ABREM, caberia lembrar que recortes e problemáticas de pesquisas são construídos por pesquisadores. E sua presença ou ausência em currículos, também. Ter em vista esta dimensão não os torna, a priori, ilegítimos nem aleatórios. Contudo, os torna objeto de debate e disputa por legitimidade, conforme se tem observado. É isto que a nota expressa quando aborda concepções, 
disputas, escolhas, seleções e recortes na área, e menciona que o problema não é o estudo de história nacional, com enfoques à história indígena e africana, mas "fazer essa incorporação em detrimento de processos históricos que dão sentido ao mundo atual e mesmo às trajetórias dos povos dos continentes africano e americano após o final do século XV" (ABREM, [2015], 2018).

Em outras palavras, depois do século XV, as histórias da África e da América se entrelaçariam e a chave inexorável de compreensão desse processo se daria pela presença europeia nestas espacialidades. Este recorte ou a forma de percebê-lo não seria eurocêntrico, sugere. Apreendê-lo significaria aceitar a própria historicidade do processo tal qual se deu, o que por sua vez e não por acaso, deveria ser interpretado a partir dos modelos de compreensão e da experiência europeia nessas espacialidades. Mas obviamente, ao fazer e replicar esta operação, não se estaria sendo eurocêntricos. Aqui, sugiro retorno à citação que serve de preâmbulo a este texto.

Tal raciocínio me fomentou inquietações impertinentes, antecipo: esta posição é consensual? Em caso afirmativo, ela resultaria mais de pesquisas ou é antes sintoma de determinada tradição na organização curricular de história? Que outras possibilidades seriam possíveis? Estas ao menos seriam cogitáveis?

A nota do NEMED/UFPR, mencionada acima pela ABREM, depois de posicionar-se sobre a concepção de história do Núcleo, critica a BNCC entre outras falhas, pelo fato de nesta, a história "perder a dimensão do vivido e inviabilizar sua reflexão crítica". Na Base, os "processos históricos desapareceriam", não haveria mais a "dimensão universal" (NEMED, [2015] 2018) na narrativa, que por sinal, carecia de passado e era feita sem cronologia (entenda-se, perspectiva linear).

A proposta, presente no documento, sustenta a nota, ao destacar a "afro-América" ou o espaço "afro-americano", também limitaria a diversidade de experiências de outros povos, em temporalidades diversas, comprometendo a compreensão histórica dos estudantes do ensino fundamental.

Nesse sentido, como podemos excluir se queremos mostrar a importância da diversidade? Destacar a "afro-américa" ou o espaço "afro-americano" requer, primeiramente, defini-lo: ele engloba àqueles que viveram neste espaço? Desde quando? E somente "africanos" e "americanos" fizeram parte desse espaço? Quem os conformava? Sabemos bem que grupos ancestrais autóctones fazem parte deste ambiente, porém outros passaram a participar nesse mesmo espaço $e$ traziam consigo seus conhecimentos políticos, culturais, religiosos e uma constituição social gerada por séculos de experiências. Como podemos excluir os denominados "europeus" desse conjunto? Parte destes apresentou, ao longo da História, uma série de sistemas políticos que tornaram-se referência para o mundo inteiro - a monarquia; a democracia; a república; outros menos favorecidos, como a tirania, a oligarquia ou a anarquia; e ofereceram-nos a ideia de poderes de caráter militar, como o Império, que ganhou, durante o processo histórico, uma conotação territorial. Como podemos falar de Império no Brasil sem termos uma referência mínima da herança romana e medieval deste 
conceito? E como falarmos de República ou Democracia sem fazermos menção ao passado clássico e helenístico greco-romano? (NEMED, [2015] 2018).

Estas inquietações, pertinentes, desconsideram, no entanto, algumas questões: história temática não é história desprovida de temporalidade ou espacialidade. Estas apenas são acionadas a partir de outros recortes que não somente a sequência cronológica, que por sinal, parte de acontecimentos recortados, selecionados, ou seja, também construídos.

O entendimento necessário dos processos e dos conceitos citados - anarquia, tirania, monarquia, oligarquia, democracia, república, império - podem ser mobilizados por problemáticas construídas pelo professor, a partir de escolhas que obedecem aos seus critérios de elaboração, o que significa, inclusive e sobretudo, respeitar suas: formação, autonomia e compreensão da diversidade de realidades que enfrenta, seja na sala de aula, seja nos debates públicos aos quais a história é requisitada a auxiliar na compreensão. Logo, as questões apresentadas, se deslocadas e vistas sob outra perspectiva, pareciam mais se aproximar e corroborar a proposta inicial da BNCC/história do que deslocar-se dela.

Se o ex-ministro da educação, Renato Janine Ribeiro, a ABREM, o NEMED, Professores de História Antiga e Medieval do Norte e Nordeste e o Fórum de professores de História Antiga e Medieval confluíam no reclame sobre a suposta ausência de conteúdos substanciais destas subáreas no currículo, "sacrificados" em detrimento das histórias africana e brasileira - chegou-se a acusar o documento de nacionalista, ufanista, "brasilcêntrico"; o GT de História da África da ANPUH-BR e a Associação Brasileira de Estudos Africanos, em nota conjunta reconheceram a importância da temática no currículo, entrementes, destacaram a ausência de conteúdos que seriam também fundamentais, bem como as deficiências de abordagem notadas, sendo a Base apontada, inclusive, como eurocêntrica.

É preciso apontar que o destaque dado à área de História da África na proposta atual da BNCC é de grande importância e fornece uma contribuição para o ensino de História e para o enfrentamento dos atuais desafios à plena integração social e ao exercício da cidadania no Brasil. Contudo, causa incômodo e estranheza aos historiadores brasileiros, estudiosos da África e promotores de vários eventos, debates e publicações sobre ensino e pesquisa, a elaboração de uma proposta curricular nos termos apresentados na BNCC. Os conteúdos relativos a esse campo do conhecimento não contemplam toda a complexidade das organizações sociais, culturais e políticas africanas, necessária à compreensão da História do continente.

A proposta parece desconsiderar os conhecimentos apresentados por uma historiografia contemporânea internacional, inclusive africana e brasileira sobre África. Essa historiografia contemporânea é crítica à perspectiva eurocêntrica, sobretudo no que se refere à abordagem das sociedades africanas que privilegia as noções de estado e formações políticas centralizadas e hierarquizadas. (GT DE HISTÓRIA DA ÁFRICA/ANPUH-BR; ABE-ÁFRICA, [2016], 2018). 
A nota se estende em oferecer exemplos. Todavia, a reprodução deles aqui alongaria mais ainda este texto. O cerne da questão que tento evidenciar é a maneira segundo a qual os conteúdos continuam a ser o fio condutor que mobiliza e orienta a maior parte das críticas.

O pronunciamento da Associação Nacional de História - ANPUH-BR, adensa o debate, tanto por aquilo que está expresso nele quanto pelo que não é dito. A nota começa por fazer um histórico da entidade, no qual se qualifica e se apresenta como fórum preocupado e atento às questões atinentes ao ensino de história, inclusive na educação básica, desde sua fundação; discorre sobre um dos marcos legais que teriam mobilizado a construção da Base (menciona a Lei 13.005/2014, que estabelece o Plano Nacional da Educação); se posiciona, alegando estranhar a celeridade na condução do processo pelo MEC; requer o dilatamento de prazos; questiona procedimentos adotados na formação da comissão da área, cuja constituição não contemplaria a diversidade necessária, mesmo que parte dos membros fosse a ela filiados; reclama o fato da entidade não ter sido consultada pelo ministério; alerta para os "nexos entre a atual proposta de BNCC e a formulação de exames nacionais", o que exigiria "aprofundar o debate sobre estes vínculos e esclarecer as concepções que fundamentam o currículo e os processos avaliativos, pensados no âmbito de política para a Educação Básica", de maneira a evitar reduzir o documento "aos estreitamentos de um currículo avaliado" (ANPUH-BR, [2015] 2018) e conclui indicando ações e encaminhamentos a serem observados e/ou orientados:

Por fim, destacamos que, até o momento, nossa entidade não foi convidada formalmente pelo MEC para integrar os debates em andamento, nem instada a se manifestar sobre o texto proposto para o ensino de História. A participação de vários associados nas discussões e na própria equipe responsável pela elaboração do documento, e a promoção de vários encontros e debates por nossas regionais, nos credencia como agentes do debate, mas não formaliza a entidade para a condição de agente interlocutor do processo de discussão e reformulação do texto curricular de História.

Assim, com o intuito de contribuir produtivamente para o debate, solicitamos uma audiência com o secretário de Educação Básica, Sr. Manoel Palacios da Cunha e Melo, com representantes de nossa entidade, para tratar dos seguintes tópicos:

1. A alteração do calendário com a ampliação do prazo para discussão do documento e da agenda de debates com o credenciamento formal das entidades para participação neste processo.

2. Reformulação da equipe de História com a ampliação do grupo de especialistas visando incluir as diferentes subáreas da História. (ANPUH-BR, [2015] 2018).

O posicionamento da ANPUH-BR se situa entre controverso e reativo. Controverso por expressar não ter sido formalmente acionada pelo MEC, do que se infere ter conhecimento, ao menos "informal", das ações encaminhadas pelo ministério. Também porque poderia, na condição de entidade representativa dos profissionais da área, condição que reafirma, e tendo em 
vista a Constituição e a LDB já mencionadas, ter se antecipado ao menos em duas décadas ao MEC, feito a discussão entre os profissionais das diversas subaéreas e apresentado proposta, o que a levaria, inevitavelmente, a assumir participação ativa no processo, em detrimento de se colocar de forma reativa às proposições em curso. Mais ainda, porque conforme explicitado na nota, tal discussão já era realizada por Seções Regionais da entidade, em eventos e debates promovidos por seus associados, partes destes, inclusive, pesquisadores que atuam na área e compuseram a equipe designada pelo ministério.

Fundada em 1961, em São Paulo, a então Associação Nacional dos Professores Universitários de História/ANPUH, a despeito de manifestar preocupação constante frente as políticas públicas no tocante ao ensino de história, no que se incluía o ensino deste na educação básica, só passaria a aceitar professores dos $1^{\circ}$ e $2^{\circ}$ graus em 1977 . Este fato, reconhecido e apontado com orgulho por parcela dos filiados, não se deu sem conflitos, o que à época, levou a divisão da entidade.

Mesmo com a atenção dispensada às questões relacionadas à educação básica e contando com quadros militantes em defesa do ensino de história, esta subárea, viu-se, paulatinamente relegada a segundo plano na entidade. Neste percurso, de fórum político a ANPUH-BR foi tornada, cada vez mais, fórum acadêmico.

Ao dizer que a entidade deslocou-se da centralidade do debate político ao debate acadêmico $^{20}$, quero ponderar que sua atuação passou a privilegiar, cada vez mais, à organização de eventos (Simpósios nacionais e regionais), Grupos de Trabalhos das subáreas, publicações especializadas (Revista Brasileira de História, História Hoje ${ }^{21}$ ), participação em fórum de pósgraduação, centrando-se sobretudo em questões relacionadas à pesquisa; em detrimento $e$ prejuízo do debate e promoção de políticas públicas no campo do ensino, no que se incluiria, fundamentalmente, a estrutura curricular e o ensino do componente na educação básica.

Assim, a dimensão política de sua atuação, no que se incluem as políticas públicas relacionadas ao ensino de história, acabaram relegadas a segundo plano. Em parte, tal comportamento se deveu a compreensão limitada, por vezes estereotipada, a respeito desta subárea.

Durante bastante tempo - suponho que os vestígios dessa visão sejam ainda evidentes - o ensino de história foi percebido por parcela considerável dos pesquisadores vinculados a outras subáreas da disciplina, como discussão menor. Não raro, era confundido ou relacionado a "dicas" de cunho instrumental ou tecnicista, cuja finalidade consistiria em sugerir estratégias de uso para tal ou qual recurso didático em sala de aula (jornal, revista, rádio, retroprojetor, lousa, televisor, computador); como organizar seminários; discutir maneiras de tornar a aula "dinâmica" e 
sugestões do gênero. Sem deixar de reconhecer a importância de o professor dominar essas estratégias, nem de longe as discussões sobre ensino de história se resumem a estes pontos, indo muito além e colocando-se no centro de debates que envolvem a teoria, a produção historiográfica $e$ a didática da história ${ }^{22}$.

A própria constituição de fóruns de debates específicos, envolvendo pesquisadores $e$ militantes do ensino de história, exemplos da Associação Brasileira de Ensino de História/ABEH e dos Encontros Nacionais de Pesquisadores do Ensino de História $^{23}$ e Perspectivas do Ensino de História $^{24}$, denota por um lado, a especialização acadêmica dessa subárea; e por outro, a desistência ou desmotivação em manter o diálogo mais amplo e efetivo com outras subáreas, algo explicitado, entre outros, pela constituição de Grupos de Trabalho/GTs na ANPUH (na nacional em suas seções regionais), cuja tendência é centrar-se, cada vez mais, na discussão especializada e pouco afeita ao debate sobre como cada subárea poderia estabelecer pontes com o ensino do componente na educação básica.

A hipótese que ora sugiro sobre a posição reativa de associações de profissionais de história em subáreas diversas, parte do seguinte ponto: o debate acalorado e intenso em torno da BNCC da área finalmente tornou evidente, a grande parte dos pesquisadores de outras subáreas, que o legitimador, a função de ser e existir dos cursos de licenciatura em história nas Universidades, é a presença deste componente na educação básica. Assim, a permanência ou existência dessas subáreas, tais como existem, depende de sua continuidade no currículo escolar.

A proposição de um currículo mínimo para a história, sobretudo nos termos em que foi colocado, com força de lei, teria potencial para mexer na estrutura dos cursos de graduação ofertados no país inteiro, posto que rompia a segmentação quadripartite, recorrentemente criticada e igualmente replicada em quase totalidade dos cursos da área pelo país.

As manifestações públicas da ANPUB-PB e de parte de suas seções regionais, além de entidades vinculadas a subáreas específicas, evidenciam, suponho, a seguinte questão: as universidades teriam de adequar seus cursos à nova realidade. Logo, a intensa discussão em torno da manutenção dos conteúdos ditos substantivos por essas subáreas no ensino básico, tornam evidente a percepção de que, a despeito do brilhantismo acadêmico e das pesquisas de ponta realizadas na academia, é no chão da escola que a história ganha vida. É lá que ela precisa ser significativa e ter um sentido para permanecer no currículo, ao ponto do estudante ser "convidado" a conhecê-la.

Sugerir que a organização curricular temática eliminaria conteúdos e a temporalidade - ou cronologia - da história, passa por um entendimento curto, apressado da discussão. Todavia, ao fazerem eco à permanência dos conteúdos substantivos no currículo do componente, as subáreas 
projetam outros objetivos, por vezes ditos de forma direta, conforme explicitado pela ABREM, por vezes nas entrelinhas, algo que se denota nas manifestações da ANPUH, ao retomar a necessidade de diálogo com as demais subáreas.

A defesa reiterada dessas entidades dos chamados conteúdos substantivos no currículo, passa assim, pela manutenção das grades curriculares dos cursos de graduação de história tal qual se apresentam desde antanho, em que pese as frequentes críticas desses profissionais. Assim, a manutenção de PPCs estruturados em disciplinas de conteúdo ou processo histórico; disciplinas de teoria, história da historiografia e metodologia (que formariam o pesquisador); e por fim, disciplinas ditas pedagógicas, cuja finalidade seria formar o professor, me parece elucidativa da historicidade formativa de nossa área.

Essa estruturação, comum a quase totalidade dos cursos de história no país, é o que legitima a realização de concurso em subáreas e garante financiamento à pesquisas, publicações de livros e periódicos, realização de eventos e proposição de Programas de Pós-graduação.

Ao buscarem o diálogo e interseções com o currículo do ensino básico, quem sabe as diversas subáreas da história atentem para o fato de que elas também são formadoras de professores e que talvez, a melhor contribuição que podem oferecer ao ensino básico, seja formar bons profissionais para atuar na escola, onde estes poderão aprender e ensinar, contar, encantar e levar estudantes a refletirem sobre o mundo por meio deste componente.

Neste sentido, mais importante do que indicar conteúdos substantivos por subárea, é buscar responder a questionamentos tais como: de que maneira se ensina e aprende história antiga, medieval, moderna e contemporânea nas escolas? Essas subáreas, caso continuem a existir no modelo quadripartite, se justificariam por si mesmas na educação básica ou precisariam, efetivamente, elaborar estratégias que aproximem seus objetos investigativos da formação de professores e do currículo da área no ensino do componente em outros níveis?

A preocupação com a formação profissional nas universidades e o ensino de história na escola básica precisa ultrapassar a listagem e a atualização dos conteúdos em cada subárea, como se a última pesquisa defendida na academia tivesse de ser levada de imediato à sala de aula, missão impossível, dada a quantidade de artigos, coletâneas, livros, dissertações e teses publicadas todos os anos. Mesmo sendo consideração recorrente e sob o risco da obviedade, cabe ponderar que o objetivo do ensino de história na educação básica é formar o cidadão, não historiadores mirins.

Há de se pensar também que inexiste modelo acabado de democracia. Ela é menos essência e mais um regime de embates e debates na busca por consensos básicos, os quais permitam a convivência em sociedade. Foge, assim, a modelos essencialistas ou idealizados. A 
elaboração de currículos é oportunidade singular para perceber e compreender parte desses dilemas.

A guisa de exemplo, tome-se as discussões sobre gênero e diversidade, excluídas do texto final da base. Numa sociedade em que cada vez mais se notabiliza a força de grupos que negam à diversidade garantida na Carta de 1988, onde será assegurado o direito à existência de grupos que por não serem majoritários, se situariam à margem - uso margem no sentido fronteiriço que o termo abarca - das escolhas defendidas e apregoadas pelas maiorias que ora se formam?

A democracia seria o regime no qual a maioria simplesmente faz valer e prevalecer sua força, enquanto silencia e inferioriza minorias? Ou ela se consubstancia no respeito às maiorias formadas, mas permitindo e legitimando a existência das minorias, sob o viés da convivência e do respeito à diversidade, garantindo-lhes direitos básicos?

Estas são colocações que podem parecer fugidias e deslocadas das discussões sobre formulação de currículos. Mas só parecem. Elas dizem, mais do que nunca, a respeito dos debates e embates que se situam neste campo. Tanto o é que mediante a omissão propositiva, tanto de entidades representativas de profissionais da área; quanto na ausência de enfrentamento da questão pelo MEC, foram os editores e autores de livros didáticos quem definiram, no final das contas, o currículo básico da educação no país. Este era, por assim dizer, um exemplo de elaboração plural e democrática?

\section{Considerações finais}

Da riqueza proporcionada pelo debate em torno da BNCC, a percepção mais recorrente quando se trata do currículo de história na educação básica, é que ele não deveria ser "mínimo", mas "máximo". Qual seja, deveria conter os relatos que abarcassem toda experiência humana na terra, bem como todas interpretações sobre esta trajetória, no que se incluiria a atualização das pesquisas sobre os temas das diferentes subáreas e suas concepções do que seja a história. De um currículo mínimo, a tendência seria um currículo infindável e irrealizável. A construção dele seria operada menos por seleções e escolhas e mais pela soma sempre crescente de conteúdos.

Um norte a se refletir, me parece, seria focar nos objetivos a serem alcançados e no público ao qual se destina tais formulações. Outro, atentar para a colonialidade das relações de poder e saber que envolvem a experiência histórica nessa espacialidade. Neste sentido, indago: as críticas e ponderações públicas apresentadas a primeira versão da Base levaram mais em conta a necessidade de existência e fortalecimento de suas subáreas ou a preocupação na maneira como elas podem dialogar com o ensino de história na educação básica? 
A hipótese que procurei apresentar e desenvolver à questão foi que o que esta(va) em disputa era mais a configuração e a existência dessas subáreas e menos o despertar para o premente e necessário diálogo delas, seja com o ensino de história na educação básica, seja com a formação de professores que atuam neste nível de ensino. Se tal hipótese tiver algum sentido de ser, existiria, então, saldo positivo nesse processo?

Em síntese, as críticas a BNCC giravam em torno da divergência sobre a concepção de história, a ausência de conteúdos considerados substantivos, a ameaça a autonomia de escolas e professores da educação básica na construção de seus currículos, proposta homogeneizadora, condução pouco transparente e democrática no processo de elaboração, tempo exíguo para avaliação, desconfiança a respeito das motivações que levaram a iniciativa do MEC, questionamento da competência dos membros da comissão para elaborar a minuta dela.

Estas foram ponderações e contribuições importantes e que certamente, serviram para despertar grande parte dos colegas de subáreas diversas para a importância do ensino de história e da constituição do currículo mínimo a ser desenvolvido nas escolas. Para muitos, operou-se o válido exercício de debater e propor as concepções de história que devem se fazer presentes na sala de aula e justificar porque suas pesquisas, depois tornadas conteúdos, devem figurar no currículo de história da educação básica.

É fundamental não desconsiderar a relevância, a grandeza, o significado dessa operação. Poucas vezes percebeu-se tantas subáreas, afeitas e circunscritas geralmente ao mundo das suas pesquisas e às relações com seus pares, se deslocarem para justificar e argumentar porque tal $e$ qual conteúdo é substancial e deve ser ensinado nas escolas brasileiras.

Resta saber se atentaram, em primeiro plano, para o fato de que o sentido de existir dos cursos de graduação de história está na existência e permanência da história no currículo do ensino básico e não o oposto. E em segundo, para o fato de que o ensino e a aprendizagem precisam ser significativos, ter sentido para os estudantes, o que desconfio, não é o mesmo que justificar a presença de tal ou qual conteúdo porque as pesquisas receberam financiamento de agências de fomento.

Para evitar omissões e esquecimentos, concluo com a seguinte informação: em 06 de abril de 2017, em matéria assinada por Letícia Carvalho, no portal de notícias G1, já no governo Michel Temer, era apresentada a terceira versão da BNCC para o ensino fundamental. Sobre nossa área, a chamada destacava: "Conteúdo de história passa a ser organizado segundo a cronologia dos fatos". (G1, [2017], 2018). 


\section{Referências}

ABREM [2015]. Carta da ABREM sobre a Base Nacional Comum Curricular (BNCC). Disponível em: $<$ https://pt.scribd.com/document/379170392/Carta-da-ABREM-sobre-a-BNCC-I-1-pdf>. Acesso em: 18 de outubro de 2018.

ADICHIE, Chimamanda Ngozi. A historiadora obstinada. In: ADICHIE, Chimamanda Ngozi. No seu cabelo. São Paulo: Companhia das Letras, 2017, p. 212-233.

ADICHIE, Chimamanda Ngozi [2009]. O perigo da história única. Disponível em: $<$ https://www.youtube.com/watch?v=EC-bh1YARsc >. Data de acesso: 16 de outubro de 2018.

ANPUH [2015]. Nota da Associação Nacional de História sobre a Base Nacional Comum Curricular - BNCC. Disponível em: <https://anpuh.org.br/index.php/2015-01-20-00-01-55/noticias2/noticias-destaque/item/3140nota-da-associacao-nacional-de-historia-sobre-a-base-nacional-comum-curricular-bncc>. Acesso em 20 de outubro de 2018.

BERSTEIN, Serge. A cultura Política. In: RIOX, Jean-Pierre \& SIRINELLI, Jean-François. Para uma história culturaı. Lisboa: Editorial Estampa, 1998, p. 349-363.

BERSTEIN, Serge. Culturas políticas e historiografia. In: AZEVEDO, Cecília. et all. (orgs.). Cultura politica, memória e historiografia. Rio de Janeiro, Editora FGV, 2009, p. 29-46.

BRASIL. Base Nacional Comum Curricular. $1^{\circ}$ ed. Brasília, 2015.

BRASIL. Constituição [1988]. Constituição da República Federativa do Brasil. Disponível em: <http://www.planalto.gov.br/ccivil 03/Constituicao/Constituicao.htm>. Data de acesso: 17 de outubro de 2018.

BRASIL. Lei no 9.394, de 20 de dezembro de 1996 (Lei de Diretrizes e Bases da Educação Nacional). Disponível em: <http://www.planalto.gov.br/ccivil 03/leis/L9394.htm>. Data de acesso: 17 de outubro de 2018.

BRASIL. Parâmetros Curricuiares Nacionais: história e geografia. Brasília: MEC/SEF, 1997.

DUSSEL, Enrique. Europa, modernidade e eurocentrismo. In: LANDER, Edgardo (org.). A colonialidade do saber: eurocentrismo e ciências sociais. Perspectivas latinoamericanas. Buenos Aires: Colección Sur Sur, CLACSO, 2005, p. 24-32.

FREITAS, Itamar. Reformas educacionais e os currículos nacionais para o ensino de história no Brasil republicano (1931/2009). Cadernos de História da Educaşão(UFU. Impresso), v. 12, 2013, p. 187-203. 
G1 [2015]. Curriculo de história sem Tiradentes é criticado por ex-ministro da Educação. Disponível em: <http://g1.globo.com/educacao/noticia/2015/10/janine-diz-que-falta-de-repertorio-em-novo-curriculoproposto-para-historia.html>. Data de acesso: 18 de outubro de 2018.

G1 [2017]. 3a versão da base curricular para ensino infantil e fundamental é apresentada; conselho vai avaliar. Disponível em: https://g1.globo.com/educacao/noticia/3-versao-da-base-curricular-para-ensino-infantil-efundamental-e-apresentada-conselho-vai-avaliar.ghtml>. Data de acesso: 21 de outubro de 2018.

GT DE HISTÓRIA DA ÁFRICA/ANPUH-BR; ABE-ÁFRICA, [2016]. Nota do GT de História da África da ANPUH Brasile da Associação Brasileira de Estudos Africanos (ABE-África) sobre a proposta da Base Nacional Comum Curricular (BNCC) para o ensino de história. Disponível em: <https://www.anpuh.org.br/index.php/bncchistoria/item/3322-nota-do-gt-de-historia-da-africa-da-anpuh-nacional-e-da-associacao-brasileira-de-estudosafricanos-abe-africa-sobre-a-proposta-da-base-nacional-comum-curricular-bncc-para-o-ensino-de-historia>.

Data de acesso: 19 de outubro de 2018.

LANDER, Edgardo (org.). A colonialidade do saber: eurocentrismo e ciências sociais. Perspectivas latinoamericanas. Colección Sur Sur, CLACSO, Ciudad Autónoma de Buenos Aires, Argentina. setembro 2005. Disponível em: $<\underline{\text { http://biblioteca.clacso.edu.ar/ar/libros/lander/pt/lander.html }>.}$

MIGNOLO, Walter D. A colonialidade de cabo a rabo: o hemisfério ocidental no horizonte conceitual da modernidade. In: LANDER, Edgardo (org.). A colonialidade do saber: eurocentrismo e ciências sociais. Perspectivas latinoamericanas. Bueno Aires: Colección Sur Sur, CLACSO, 2005, p. 33-49.

MIGNOLO, Walter D. Desobediência epistêmica: a opção descolonial e o significado de identidade em política. Cadernos de Letras da UFF: Dossiê: Literatura, língua e identidade, n. 34, 2008, p. 287-324. Disponível em:

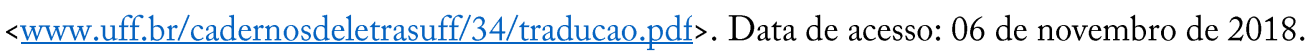

MIGNOLO, Walter D. Histórias Locais/Projetos Globais. Colonialidade, saberes subalternos e pensamento liminar. Belo Horizonte: Editora UFMG, 2003.

NEMED-UFPR [2015]. NEMED sobre o BNCC História especialmente o Ensino Médio. Disponível em:

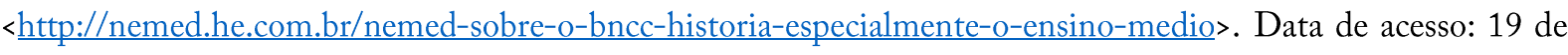
outubro de 2018.

OLIVEIRA, Margarida Maria Dias de. O Direito ao passado. Uma discussão necessária à formação do profissional de História. Aracaju: Editora UFS, 2011.

OLIVEIRA, Margarida Maria Dias de; FREITAS, Itamar. Base Nacional Comum Curricular: caminhos percorridos, desafios a enfrentar. In: CAVALCANTI, Erinaldo. et ai. (org.). História: demandas e desafios do tempo 
presente. Produção acadêmica, ensino de História e formação docente. São Luís: EDUFMA, 2018, p. 49-63. Ebook disponível em: $<$ https://itemnpo.unifesspa.edu.br/component/content/article.html?id=113 $>$.

QUIJANO, Aníbal. Colonialidade do poder, eurocentrismo e América Latina. In: LANDER, Edgardo (org.). A colonialidade do saber: eurocentrismo e ciências sociais. Perspectivas latinoamericanas. Buenos Aires: Colección Sur Sur, CLACSO, 2005, p. 107-130.

SADDI, Rafael. O parafuso da didática da história: o objeto de pesquisa e o campo de investigação de uma didática da história ampliada. Acta Scientarum. Maringá, v. 34, n. 2, 2012, p. 211-220.

SILVA, Matheus Oliveira da. BNCC e o componente curricular História: como pensaram os seus críticos? Boletim Historiar, Aracaju, n. 23, 2018, p. 85-106.

\footnotetext{
${ }^{1}$ Texto apresentado à mesa-redonda "Dilemas da Base Nacional Comum Curricular no século XXI: narrativas em disputas", durante a VI Semana de História - Ensinar e escrever história no século XXI: desafios, perspectivas e possibilidades, realizada pelo curso de História da Universidade Federal de Rondônia/Unir, campus de Rolim de Moura/RO. O uso predominante da primeira pessoa guarda relação com as circunstâncias da apresentação e porque a despeito dos débitos e empréstimos aos autores citados e a outros cuja memória não foi capaz de enumerá-los, trata-se de leitura bastante pessoal do processo. Assim, considerei pouco ético me ancorar ou atribuir a responsabilidade por tais posicionamentos a terceiros.

${ }^{2}$ Em respeito a historicidade dos documentos e referências consultadas, destaco, entre colchetes, o ano de sua produção/publicação inicial.

${ }^{3}$ A discussão é rica e extensa e o número de teóricos envolvidos também. Uma boa síntese pode ser encontrada na coletânea organizada por Edgard Lander (2005).

${ }^{4}$ A este respeito, ver: Itamar Freitas (2013).

${ }^{5}$ Sobre cultura política, consultar: Serge Berstein ([1997]1998) e (2009).

${ }^{6}$ Em respeito a historicidade dos documentos e referências consultadas, destaco, entre colchetes, o ano de sua produção/publicação inicial.

${ }^{7}$ Aqui, no sentido de lei.

${ }^{8}$ A respeito desta organização curricular, Maria de Dias Oliveira e Itamar Freitas (2018, p. 53) ponderam que ela foi incorporada aos PCN, os quais não romperam com a perspectiva de que o ensino de história deveria dar conta de toda a experiencia humana pregressa: "[..] o conhecido quadripartidarismo francês que, na verdade, é alemão e já dura seis séculos. O fato de apresentar-se com uma nova roupagem - a história temática - em nada prejudicou a sua circulação". ${ }^{9}$ Este estudo não será realizado aqui. Trata-se de sugestão.

${ }^{10}$ Para fins de esclarecimentos e no sentido de evitar ruídos ao entendimento, trato aqui história como área e as especialidades na qual é constituída - ou subdividida - por subáreas.

${ }^{11} \mathrm{O}$ uso das terminologias nacional e nação devem ser compreendidas aqui em seu sentido espacial-geográfico. Faço esta ressalva por entender que partir da espacialidade brasileira não significa o mesmo que produzir ou investir em narrativas marcadas por um nacionalismo ufanista, conforme foi sugerido por algumas das críticas a esta versão da Base. ${ }^{12}$ Exploro situações fora da BNCC para dialogar com ela pelos seguintes motivos: desejei aproximar a discussão de minha subárea de atuação no curso de graduação (história moderna e contemporânea), do meu tema de pesquisa atual (narrativas de progresso na Amazônia Ocidental) e do lugar onde atuo como professor (mesorregião do leste rondoniense). Assim, preferi criar exemplos próprios, ao invés de citar textualmente trechos da Base que poderiam contemplar este ponto. Esta escolha é também um esforço para evidenciar que os conteúdos das subáreas da história podem ser adequados pelo docente a partir de recortes construídos por ele.

${ }^{13}$ Não entrarei aqui na discussão teórica a respeito da denominação desses recortes, que não são estanques e podem ser operacionalizados de formas diversas.

${ }^{14}$ Um estudo inicial e bastante elucidativo sobre a recepção da BNCC do componente história por entidades representativas de profissionais desta área, foi realizado por Matheus Oliveira da Silva (2018), em projeto de pesquisa PIBIC, orientado pela profa. Margarida Maria Dias de Oliveira/Departamento de História/UFRN, cujos resultados foram apresentados em artigo publicado recentemente. A referência está indicada ao final deste.
} 


\footnotetext{
${ }^{15} \mathrm{~A}$ este respeito, relato bastante elucidativo foi apresentado por parte dos membros da Comissão e pode ser encontrado em: (Oliveira; Freitas, 2018). Conforme ver-se-á, o próprio ex-ministro assumiu de público ter vetado a proposta, desconsiderando-a documento daquele ministério.

${ }^{16} \mathrm{O}$ texto da nota segue na íntegra.

${ }^{17}$ Pululam, sobretudo entre profissionais de história, relatos e reclames de que o brasileiro não gosta e não valoriza a história. Todavia, é provável que exista outras perspectivas a respeito, principalmente quando grupos de influência negam determinado viés historiográfico e num revisionismo, mesmo tosco, tentam reestabelecer o que entendem ser a "verdade histórica". Esse movimento é amplo, congrega militantes menos destacados, mas atinge também deputados, senadores e até ministros do Supremo Tribunal Federal/STF. Um destes, inclusive, recentemente defendeu, de público, o uso da terminologia "movimento de 1964", em detrimento de "golpe de 1964". Mesmo no STF, ele não parece estar sozinho na empreitada do revisionismo histográfico nacional.

${ }^{18}$ Possui graduação, mestrado e doutorado em filosofia. Mais detalhes a respeito de sua formação e atuação profissional podem ser acessados no currículo Lattes: http://lattes.cnpq.br/9987610379141827

${ }^{19}$ Devo estas informações também ao mencionado estudo de Matheus Oliveira da Silva (2018), no qual consta cronologia dessas manifestações e a categorização das principais críticas à Base. Uma compilação desses posicionamentos foi feita pela Seção Regional da ANPUH-RJ, em aba específica, no sítio da entidade e pode ser acessada no seguinte endereço: https://anpuh.org.br/index.php/bncc-historia.

${ }^{20}$ Em sua tese de doutorado, defendida em 2003, a profa. Margarida Maria Dias de Oliveira (2011) faz análise bastante elucidativa sobre a atuação da ANPUH-BR no debate político nacional até aquele momento, sobretudo no que diz respeito ao ensino de história $e$ a formação de profissionais da área.

${ }^{21}$ Inclusive, voltada à subárea do ensino.

${ }^{22}$ A este respeito, ver a discussão de Saddi (2012).

${ }^{23}$ Encontra-se na XI edição.

${ }^{24} \mathrm{O}$ X encontro foi realizado este ano, em Porto Alegre/RS.
} 